\title{
Grief Following Miscarriage: A Comprehensive Review of the Literature
}

\author{
NORMAN BRIER, Ph.D.
}

\begin{abstract}
Objective: The literature exploring the relationship between miscarriage and grief is sparse. This paper summarizes the literature on grief subsequent to an early miscarriage to elucidate the nature, incidence, intensity, and duration of grief at this time and to identify potential moderators.

Methods: An electronic search of the Medline and Psych Info databases was conducted. Studies were selected for inclusion if they related to early miscarriage, used a standardized measure to assess perinatal grief, and specified the assessment intervals employed. Qualitative studies were included when helpful to develop hypotheses.

Results: Descriptions of grief following miscarriage are highly variable but tend to match descriptions of grief used to characterize other types of significant losses. A sizable percentage of women seem to experience a grief reaction, with the actual incidence of grief unclear. Suggestively, grief, when present, seems to be similar in intensity to grief after other types of major losses and is significantly less intense by about 6 months. Few conclusions can be drawn in regard to potential moderators of grief following a miscarriage.

Conclusions: Although additional research is clearly needed, guidelines for coping with grief following miscarriage can be based on the data available on coping with other significant types of losses. Given the range of potential meanings for this primarily prospective and symbolic loss, practitioners need to encourage patients to articulate the specific nature of their loss and assist in helping them concretize the experience.
\end{abstract}

\section{INTRODUCTION}

A MISCARRIAGE, OR SPONTANEOUS ABORTION, is a psychologically challenging event. Unlike the loss of other family members, the grieving individual has had few direct life experiences or actual times with the deceased to review, remember, and cherish. There is no publicly acknowledged person to bury or established rituals to structure mourning and gain support, and, often, relatively few opportunities are present to ex- press thoughts and feelings about the loss due to the secrecy that often accompanies the early stages of pregnancy. When others do know about the loss, they often fail to appreciate its impact or minimize it, making comments such as, "It was not meant to be" or "It is for the best."1-7

Although there is increasing acceptance that a miscarriage represents a significant loss experience, ${ }^{4}$ the empirical literature relating grief to miscarriage continues to be limited by several significant problems. The term "grief" itself tends to

Department of Psychiatry and Pediatrics, Albert Einstein College of Medicine of Yeshiva University, Children's Evaluation and Rehabilitation Center, Bronx, New York. 
be poorly and inconsistently defined. 8,9 The scales used to measure grief following miscarriage have varied in their reliability and validity, the breadth of signs of grief that are measured (for example, at times including markers of depression and at times yearning for the lost pregnancy and baby), and the definition of the central construct underlying measures of perinatal grief tend either not to be specified or to vary across scales. ${ }^{10,11}$ In addition, the assessment intervals used in studies have ranged widely. As the intensity of grief is significantly affected by the passage of time, ${ }^{12,13}$ the use of varying assessment points confounds results. In addition, some studies have measured grief while symptoms are being directly experienced, whereas other studies measure grief retrospectively so that descriptions of grief are primarily based on recall. Finally, pregnancy loss in studies of grief is sometimes viewed as a unitary category in which distinctions between early and late miscarriages, ectopic pregnancies, stillbirths, and neonatal deaths are blurred.

Consequently, this review comprehensively surveys the literature on grief following miscarriage. It emphasizes studies that have focused on grief in regard to early miscarriage, specified the assessment intervals used so that the time since loss can be considered, and used a reliable and valid measure to assess prenatal grief. Qualitative studies are included when the results can be employed to develop hypotheses. The purpose of this review is threefold: to elucidate the nature of grief following an early miscarriage; to determine the incidence, intensity, and duration of grief at this time; and to identify the variables that potentially moderate its intensity and duration. As a result of this analysis, clinicians will be better able to understand the nature and course of their patients' grief following miscarriage and thereby better help patients cope. Patients, in turn, will be more likely to feel that the import of their loss is recognized and understood and be able to acquire clearer expectations as to what they are likely to feel and for how long.

First, the terms grief and miscarriage are defined. Next, the nature, duration, and intensity of grief following miscarriage are discussed, including differences in grief associated with gender. Key moderators are then noted. In the final section, the research and clinical implications of the review are described.

\section{MATERIALS AND METHODS}

An electronic search of the Medline and Psych Info databases was conducted covering the period from January 1966 through January 2007 using the keywords miscarriage, spontaneous abortion, pregnancy loss in combination with grief, mourning, and bereavement. Further searches were then carried out using references cited in the identified papers. Searches were not circumscribed by date or by language if an English abstract was available. Studies were subsequently included in the review if the majority of women in a study sample (i.e., at least $51 \%$ ) experienced an early miscarriage (i.e., before the 20th week of gestation), a standardized measure of perinatal grief was used, and assessment intervals were clearly specified. Qualitative studies, as noted, were included when helpful in formulating hypotheses.

\section{Grief defined}

Grief refers to the affective, physiological, and psychological reactions to the loss of an emotionally important figure $\mathrm{e}^{14,15}$ and typically includes severe and prolonged distress. ${ }^{16}$ There is a lack of consensus as to what constitutes normal grief. ${ }^{18}$ For example, the American Psychiatric Association's Diagnostic and Statistical Manual $(\mathrm{DSM}-\mathrm{IV})^{19}$ does not note what a typical grief reaction is. Instead, the DSM-IV describes a set of symptoms that are not characteristic of a normal grief reaction, such as excessive guilt, suicidal ideation, and feelings of worthlessness.

Various authors have attempted to delineate what constitutes normal grief by describing the signs and symptoms that are typically present in the bereavement period. ${ }^{20-23}$ Prigerson et al., ${ }^{9,22}$ for example, described a holistic set of characteristics of grief as part of their effort to distinguish complicated and normal grief. Organizing the descriptors into affective, behavioral, cognitive, and physiological categories, they noted that, affectively, people are depressed, despairing, dejected, angry, and hostile. Behaviorally, they tend to act agitated and fatigued, cry spontaneously, and are socially withdrawn. Cognitively, they are preoccupied with thoughts of the deceased, have negative self-judgments, feel hopeless and helpless, have a sense of unreality, and experience memory and concentration problems. Physiologically, 
there is a loss of appetite, sleep disturbance, energy loss and exhaustion, somatic complaints, and physical complaints often similar to what the deceased endured. ${ }^{9,22}$ Yearning, or a deep longing for the deceased, has been identified in a recent study as the most salient element of grief among 233 individuals who were administered the Inventory of Complicated Grief-Revised scale. $^{23}$

Explanatory frameworks to help understand the nature of grief tend to emphasize attachment theory. ${ }^{24}$ According to attachment theory, grief is a natural product of an individual's continuing attempt to foster proximity with the object of attachment and minimize separation from him or her. As will be described, this perspective may be especially helpful in understanding an individual's tendency to experience a strong sense of yearning for an anticipated, mostly imagined relationship following miscarriage. Initially, according to attachment theory, there are energetic reactions to the absence of proximity after a loss composed of searching and protest and, subsequently, passive responses suggesting the beginning of a process of disengagement from the attachment figure. ${ }^{20,24,25}$

A Stage Theory of Grief is often used both to organize the individuals' reactions to loss $23,24,26,27$ and to address the duration of grief. Most stage theorists propose an initial stage of numbness and disbelief, followed by a stage of separation distress during which yearning for the deceased is primary, then a period of sadness and despair, and a concluding phase of recovery and reorganization. ${ }^{23,28}$ Empirical support for this sequence of stages was recently demonstrated in a longitudinal study of 233 bereaved individuals assessed over a 24 -month period. ${ }^{23}$ Additionally, all the salient distressing characteristics of grief were found to peak within 6 months, ${ }^{23}$ consistent with Jacobs' review ${ }^{28}$ of normal and pathological grief in which he noted that the normal grief process seems to be appreciably completed within 6 months after the loss of a loved one.

\section{Miscarriage defined}

Miscarriage, or spontaneous abortion, is the natural termination of a pregnancy before the fetus is considered viable. ${ }^{1,29}$ Roughly $15 \%-20 \%$ of recognized pregnancies end in miscarriage, ${ }^{30,31}$ with about three quarters occurring before the 12th week of gestation. ${ }^{32,33}$ Although clinicians generally consider pregnancies that spontaneously terminate prior to the 14th-16th weeks of gestation to be miscarriages, ${ }^{1}$ the time frames used in research studies have ranged, most typically, from up to 20 weeks of gestation ${ }^{1}$ to 27 weeks of gestation. 7,34 Miscarriage rates rise dramatically with age, from about $27 \%$ for women aged $25-29^{30}$ to about $40 \%$ for women aged $40^{35}$ to about $75 \%$ for women aged $\geq 45$. $^{36}$

Instruments and methodologies used

to assess the presence and intensity

of grief following miscarriage

Empirically, studies specifically designed to elucidate the essential characteristics of grief following a miscarriage, incorporating operational definitions of grief and miscarriage, representative samples, and a comparison group of subjects who had experienced other types of losses, could not be located. What is available as a basis for elucidating the nature of grief at this time are studies describing the development of self-report scales designed to quantitatively measure the presence and intensity of perinatal grief ${ }^{10,11,37-39}$ and qualitative studies of the experiences of women who had a miscarriage. ${ }^{40-43}$

As will be apparent, the measures developed to assess grief following miscarriage differ in terms of the types of symptoms of grief they include and their comprehensiveness. In addition, although some of the scales to be described have been developed based on a factor analysis of item pools, others have been derived based on the scale author's theoretical or clinical perspective.

The Perinatal Grief Scale (PGS) ${ }^{38}$ was one of the earliest instruments developed to assess the intensity of grief following a miscarriage. The scale was based on an established measure, the Texas Grief Inventory. ${ }^{13}$ The items selected for this scale were derived from the authors' clinical experience with people who had lost a close friend or relative and was intended to measure grief-related behaviors and feelings, such as sadness, searching for the deceased, crying, and yearning. ${ }^{38,46}$ Toedter et al. ${ }^{38}$ interviewed parents who experienced a perinatal loss and modified the wording of items based on these interviews. A condensed version of the scale was also developed. ${ }^{39}$

Factor analytical studies of the PGS have identified three subscales: active grief, difficulty cop- 
ing, and despair. Nikcevic et al. ${ }^{37}$ also adjusted the Texas Grief Inventory for miscarriage and, in a study of 227 women who suffered a miscarriage prior to the 14th week of gestation, again found a three-factor solution: pure grief, grief-related emotions, and perceived adjustment and functioning since the miscarriage. High reliability (Chronbach's alpha $=0.90)$ and construct validity for this scale were found in an initial study demonstrated by significantly lower scores reported in women who became pregnant. ${ }^{37}$

The PGS has been criticized for both overemphasizing feelings related to the "lost baby" at the expense of other potential grief-related feelings, such as yearning for the lost pregnancy, 7,37 and for overlapping too greatly with markers of depression. ${ }^{7}$ With regard to reliability, in a review of a decade of research with the PGS based on 22 studies and a sample of 2485 participants, computation of Cronbach's alpha indicated very high internal consistency. Adequate convergent validity has also been consistently demonstrated in the association of the scale with markers of mental health, social support, and marital satisfaction. ${ }^{42}$

To better distinguish grief following a miscarriage from depression, Beutel et al. ${ }^{10}$ developed the Munich Grief Scale. They modified and shortened the PGS based on a review of the literature and their own clinical observations. They found the Munich Grief Scale to be composed of several subscales, including sadness, fear of future loss, guilt, anger, and searching for meaning. They noted that feelings of missing the baby, painful memories of the loss, and difficulty relinquishing the hopes for, expectations of, and fantasies about the unborn child were important elements to be measured. Adequate reliability was reported along with adequate validity based on the scale's association with scales of depression, anxiety, and physical symptoms.

Hutti et al. ${ }^{40}$ developed a scale to measure grief following a miscarriage, entitled the Perinatal Grief Intensity Scale (PGIS). The scale was theoretically derived to predict grief intensity and was tested on a convenience sample of 186 women who suffered a miscarriage before 16 weeks of gestation in the previous 12-18 months. The three factors they identified as predictive of grief intensity following a miscarriage were the reality of the baby and pregnancy within, the congruence between the actual miscarriage and the woman's standard of the desirable (i.e., wish for a baby), and the ability of the woman to make de- cisions or act in ways to increase this congruence. The PGIS, in an initial validation study, demonstrated acceptable reliability (alpha coefficient of 0.82 ) and construct validity. All three subscales were significantly correlated with self-report of grief intensity and length of grieving. ${ }^{40}$

Finally, a recently developed, narrow measure of grief following a miscarriage, derived from a review of the theoretical, clinical, counseling, and research literature, is the Perinatal Bereavement Grief Scale (PBGS). ${ }^{11}$ An initial validation study demonstrated high internal consistency and testretest reliability. The scale is designed to measure grief following reproductive loss based on the degree to which the individual yearns for the lost pregnancy and lost baby. The intensity of grief found on the scale is associated with the individual's desire to maintain an attachment with the baby and the degree of investment the individual has had in the child. Convergent validity was demonstrated by its association with measures of attachment and investment in the child. The use of yearning as the key construct to develop the scale is validated by the recent longitudinal study of bereaved individuals, noted earlier, in which yearning was found to be the most salient psychological response to natural death. ${ }^{23}$

Qualitative studies of the experience of miscarriage have varied widely in their methodology (i.e., questionnaires, interviews, and nonstandardized Likert scales) and in their sample sizes (i.e., from 6 to 294 subjects). ${ }^{41,43-48}$ Initially, a sense of shock and unreality is described, followed by feelings of confusion over the sudden disappearance of a maternal role, and disappointment over the loss of an anticipated future. ${ }^{44,45,48}$ The intensity of grief is described as similar to the intensity of grief individuals experience after other types of significant losses, such as that of a family member. ${ }^{41,43}$ Also described are symptoms of stress, sadness, depression, guilt, and self-blame. ${ }^{43,45,47,48}$

Based on this review of the items included in standardized measures developed to assess perinatal grief, descriptions of grief following miscarriage are highly variable but, on the whole, seem to match descriptions of grief used earlier to characterize other types of significant losses. Thus, yearning, sadness, crying, fatigue, appetite and sleep changes, preoccupation with the loss, and guilt seem to be commonly noted. When guilt is present, it tends to be specifically linked to selfblame for failing to protect the baby from pain 
and death. ${ }^{8}$ Particularly evident in the qualitative studies noted, the yearning evident as part of a grief reaction following miscarriage is primarily prospective and centers on a longing for an anticipated future and set of expectations, plans, and hopes. Thus, grief after miscarriage seems, in large measure, to involve distress over the loss of a symbolic, as opposed to an actual, relationship, one constructed in idiosyncratic fashion from the mourner's imagination based on her unique needs and wishes. Again, particularly evident in the qualitative studies, grief following miscarriage seems to involve multiple elements of loss, of being a pregnant woman, a mother, and a member of a relatively larger family, with the intensity of grief attached to each element seeming to vary from mourner to mourner.

\section{Incidence, intensity, and duration of grief following miscarriage}

The literature in regard to incidence rates, intensity, and duration of grief following miscarriage is extremely sparse. With regard to incidence rates, the literature is composed primarily of qualitative studies that lack a clear operational definition of grief and use varying time intervals, formats, and measures. As a result, the incidence of grief reactions following miscarriage reported in these studies has varied widely.

Results, for example, of an early, impressionistic study of 22 women who had experienced a spontaneous abortion found that all the women displayed typical signs of grief based on clinical contacts, ${ }^{49}$ as did almost all the women (96\%) who were provided support and counseling after a miscarriage in a miscarriage clinic. ${ }^{50}$ As both of these qualitative studies involved individuals seeking counseling, the incidence of grief is likely to be elevated. In another qualitative study, using data obtained from 44 women treated for miscarriage, about 2 weeks later, on average, $82 \%$ of women were said to feel a sense of loss, and $77 \%$ experienced some limitations in daily functioning as a result of that loss. ${ }^{51}$ Finally, in an empirical study employing a matched community control group, 125 women were assessed with the $\mathrm{Mu}$ nich Grief Scale shortly after a miscarriage that had occurred before the 20th week of gestation and again at 6 and 12 months. Twenty percent of the sample had only a grief reaction, $12 \%$ had a depressive reaction, $20 \%$ had a combined depressive and grief reaction, and $48 \%$ had no change in their emotional reactions. ${ }^{3}$ Thus, although a sizable percentage of women seem to experience a grief reaction following a miscarriage, the actual incidence of grief at this time is unclear.

Whereas many studies have examined factors that might moderate the intensity of grief following a miscarriage, three studies could be located that focused on the overall, relative intensity of grief following a miscarriage. Paton et al. ${ }^{52}$ administered the PGS to 58 women 4-6 weeks postmiscarriage and found highly elevated scores. Similarly, Nikcevic et al. ${ }^{37}$ administered the Texas Grief Inventory adjusted for miscarriage to 207 women who miscarried prior to 14 weeks and obtained mean scores as high as the scores of people who had lost a close relative. Finally, Hutti et al. ${ }^{40}$ administered the PGIs, developed specifically to predict intensity of grief response to early pregnancy loss, to a convenience sample of 186 women who had experienced a miscarriage before 16 weeks of gestation in the previous 12-18 months. Roughly three fourths of participants reported moderate to intense grief reactions. Thus, based on this limited literature, when a grief reaction occurs following a miscarriage, it seems to be relatively elevated. Further, again suggestively, the intensity of grief following a miscarriage seems to be similar to the intensity of grief after other types of significant losses.

Several studies have attempted to answer the question: How long does grief endure following a miscarriage? using changes in the intensity of grief over time as a marker. Deckhardt et al. ${ }^{53} \mathrm{ad}-$ ministered a standardized questionnaire to 86 women who experienced a spontaneous abortion shortly after a dilation and curettage (D \& C) and again at 7, 13, and 24 months. For the majority of women, grief continuously declined prior to the initial follow-up assessment at 7 months. Similarly, Beutel et al. carried out two studies addressing the issue of duration of grief. In a longitudinal study using the PGS with 86 women who had an early miscarriage, grief reactions were found to gradually decline and significantly diminish by 6 months, ${ }^{10}$ and in a controlled follow-up study, 56 couples completed the Munich Grief Scale at 6 and 12 months postmiscarriage. Grief scores significantly declined after 6 months for both men and women. ${ }^{3}$ Nikcevic et al., ${ }^{37}$ in a prospective, longitudinal study administered the Texas Grief Inventory adjusted for miscarriage to 
143 women who had a pregnancy loss between 10 and 14 weeks. Grief scores were significantly lower at 4 months compared with 4 weeks postmiscarriage. Finally, Hutti et al., ${ }^{40}$ in a validation study of the PGIS with 186 women who experienced a miscarriage before 16 weeks, found that the moderately intense grieving most participants reported lasted less than 6 months, with about one half grieving less than 3 months. Thus, the available data indicate that there is a significant reduction in the intensity of grief by about 6 months postmiscarriage, suggesting that the duration of grief following pregnancy loss is similar to the duration of grief after other types of significant losses. ${ }^{23}$

One variable that seems to affect the duration of grief following a miscarriage is a subsequent pregnancy. ${ }^{7}$ Cuisiner et al., ${ }^{54}$ for example, administered questionnaires to 2140 pregnant women in a prospective study. Subsequently, 227 lost a baby by miscarriage $(85 \%)$ or perinatal death $(15 \%)$. These women were then administered the PGF at four postloss assessment intervals. The women who had a subsequent pregnancy by the time of these assessments displayed a significant decrease in grief levels compared with women who as yet had not conceived. Similarly, Nikcevic et al. ${ }^{55}$ used the Texas Grief Inventory, adjusted for miscarriage, with 207 women who had an early pregnancy loss. Grief levels in women who became pregnant following a miscarriage were significantly lower than grief levels of women who had not become pregnant. Franche ${ }^{56}$ compared the level of active grief, difficulty coping, and despair in 25 women (and their partners) who had become pregnant after a pregnancy loss with the level of active grief, difficulty coping, and despair in 25 women (and their partners) who had not become pregnant. Women who were pregnant experienced significantly lower levels of despair and difficulty coping. Grief intensity, however, remained high for both groups, suggesting that a subsequent pregnancy seems to lessen the active, impairing effects of grief while mourning still continues. Thus, these studies are somewhat consistent in indicating that the duration of grief following miscarriage is relatively shorter in women who became pregnant by the time of assessment compared with women who do not become pregnant. In addition, these studies suggest that key elements of loss following miscarriage include the loss of the roles of pregnant woman and mother so that when these roles are reestablished, symptoms of active grief lessen.

\section{Gender and intensity of grief following miscarriage}

An area in which there has been a fair amount of research relates to gender-specific differences in the intensity of grief following a miscarriage. Although a variety of standardized grief assessment instruments were used, along with widely different sample sizes and assessment intervals, men were found to experience significantly less intense levels of grief for a shorter period following a miscarriage than women in eight of the eleven studies that could be located. ${ }^{57-64}$ Of the three studies that produced somewhat contradictory results, two used only a male cohort and compared scores on the PGF with norms for women. Men's and women's scores were found to be comparable following miscarriage. ${ }^{65,66} \mathrm{Com}$ paring men's scores with test norms rather than with their female partners' scores limits the strength of the conclusion, in that time intervals since loss are not controlled. The remaining contradictory study, which found higher levels of grief in 39 men relative to their female partners soon after the miscarriage and comparable levels at 2-4 months postmiscarriage, is also limited, in this case by the small size of the sample. ${ }^{67}$ Thus, the overall trend of these findings supports the commonsense expectation that a woman's grief is relatively more intense than a man's following a miscarriage because she carried the pregnancy biologically, has a greater psychological attachment as a result, and, therefore, experiences the loss more powerfully.

Several qualitative differences between men's and women's grief have also been noted. In a study comparing couples' reactions to miscarriage, men were found to cry less, be less distressed when seeing other pregnant women, and have less need to talk about the loss. ${ }^{59}$ In a second study using an interview format with 20 male partners, a high level of confusion as to appropriate behavior and a belief that men need to deny their own feelings of grief for their partner's sake were noted. ${ }^{68}$ Men's grief following a miscarriage was found to be moderated by several variables, including the vividness of their imagery of the fetus based on exposure to an ultrasound scan ${ }^{65,66}$ and length of pregnancy in one study ${ }^{69}$ but not moderated by length of preg- 
nancy in another. ${ }^{65}$ An important caution when discussing distinctions between men's and women's affective reactions to miscarriage is that these differences may reflect differences in the expression of emotion generally rather than affective reactions to miscarriage per se. ${ }^{7}$

\section{Moderators of grief and miscarriage}

Based on the literature reviewed, the nature and intensity of individuals' reactions to pregnancy loss seem to vary. The factors that are generally seen as moderating the direction and strength of the relationship of bereavement and grief include the nature of the relationship between the bereaved and the deceased, the specific needs and wishes the individual associates with the relationship, the extent to which the deceased is an important part of the bereaved individual's mental representation of the world, the way the individual deals with emotional challenges and expresses emotions typically, and the reactions of significant others to the loss. ${ }^{8}$ These general factors are used as an organizing schema to make a somewhat arbitrary division of the potential moderators identified in the literature on miscarriage and grief.

Nature of the relationship. As noted, given the primarily prospective, symbolic nature of the relationship between the bereaved and the deceased in a miscarriage, the degree to which the individual experiences the pregnancy and relationship to the developing fetus as real and gestational age are two factors that have been noted in the literature as possibly affecting the nature and intensity of grief after a miscarriage. Fetal imaging techniques, experiencing fetal movement, and such concrete actions as naming the baby and purchasing items for the baby increase the likelihood that the deceased will be experienced as real. In addition, these experiences are likely to result in memories of actual times with him or her, ${ }^{70}$ increase the likelihood that he or she will be perceived as a baby rather than as a fetus, ${ }^{71}$ increase maternal attachment, ${ }^{7}$ and, as a consequence, ought to increase the intensity of grief following the loss.

The empirical studies relating the perceived reality of the pregnancy and the nature and intensity of grief following a miscarriage are extremely limited. The reality of the pregnancy has been identified as a factor in the three-factor solution found by Hutti et al. ${ }^{40,71}$ when developing the PGIF. Based on a convenience sample of 158 women who had experienced a miscarriage before 16 weeks of gestation in the prior 12-18 months, the more individuals had perceived the pregnancy and baby as real prior to the miscarriage, the more intense was their level of grief.

With regard to the effect of viewing an ultrasound, contradictory results have been reported. Puddifoot and Johnson ${ }^{66}$ administered the PGF and the Vividness of Visual Imagery Scale to 158 male partners of women who had miscarried prior to the 25th week of pregnancy. Men who had viewed an ultrasound were found to have significantly more vivid images of their unborn child and higher levels of grief than male partners who had not seen an ultrasound. Ritsher and Neugebauer, ${ }^{72}$ however, found a lack of association between viewing an ultrasound and level of grief. ${ }^{7}$ Some of the contradiction in findings may be explained by differences in the methodology used in the two studies. Whereas Ritsher and Neugebauer ${ }^{72}$ noted if an ultrasound was viewed, Puddifoot and Johnson ${ }^{66}$ measured not only if an ultrasound was viewed but also the degree to which vivid images resulted from the viewing. The latter may be more important in predicting the psychological impact of the loss.

Relatively higher levels of yearning after pregnancy loss after experiencing fetal movement or quickening have been reported in the one study that could be identified. ${ }^{11}$ In this validation study of the PBGS, a sample of 304 women who experienced a miscarriage (approximately three quarters before 16 weeks and the rest before 27 weeks) were assessed at 2 weeks, 6 weeks, and 6 months postmiscarriage. Women who felt the fetus move had significantly higher PBGS scores. Support was also found for a significant positive association between PBGS scores and such actions as naming the baby, thinking of what has been lost as a baby, making changes in the home in anticipation of the baby's arrival, and purchasing items for the baby. Ritsher and Neugebauer ${ }^{11}$ considered these actions to be reflections of parents' investment in the pregnancy, and they are also likely to enhance the reality of the baby and increase the number of concrete events that have occurred and can be used to create memories of the baby. Thus, given the limited and somewhat inconsistent nature of these findings, there is only partial support for the proposition that the more an individual ex- 
periences the pregnancy as real, the more intense is his or her level of grief.

Length of gestation is another factor thought to increase the reality of the pregnancy, based on the commonsense assumption that the longer the pregnancy, the greater the number of opportunities there would be to experience the baby's reality (e.g., fetal movement, ultrasound) and, therefore, the stronger the attachment to the baby. Again, very few studies could be located that have focused specifically on the relationships among gestational age, grief, and miscarriage. Further, the studies that could be located varied markedly in design, sample size, definitions of pregnancy loss, assessment instruments, and assessment intervals. Not surprisingly, therefore, the results are highly inconsistent.

Of the studies that found a positive relationship, Toedter et al. ${ }^{38}$ report a significant positive association between gestational age and grief as part of their initial development and validation study of the PGF. It is important to note, however, that the sample of 194 subjects includes women who had experienced fetal and neonatal deaths as well as spontaneous abortions. Thus, the range in gestational age was much greater than would be the case if only women who miscarried were included. Similarly, Theut et al. ${ }^{73}$ report a positive association between gestational age when women miscarry and unresolved grief during the subsequent pregnancy and postnatal period. Again, however, 16 of their 25 subjects had miscarried, and the rest had experienced stillbirths and neonatal losses. Further, the study employed a retrospective design so that subjects were recalling losses that had occurred at varying times in the last 2 years.

Goldbach et al., 57 in a follow-up study at 1 and 2 years postloss based on earlier research with the PGS, also found a positive association between gestational age and grief in 138 women whose loss occurred on average at 16.5 weeks, as did Janssen et al. ${ }^{74}$ in a longitudinal, prospective study. Janssen et al. sent a questionnaire to 2140 women within the first 12 weeks of pregnancy. Of these, 227 women subsequently miscarried and were reassessed four times over an 18-month period using the PGS. Duration and intensity of grief were positively associated with the length of the pregnancy. In addition, Franche ${ }^{56}$ reported a positive association between gestational age and symptoms of active grief based on the responses of 60 pregnant women with previous miscarriages or perinatal deaths and 50 of their partners using the PGS. Fifty-one percent of the women in the sample had a loss in the first trimester, and the mean gestational age at the time of loss was 17.5 weeks. Complicating the implications for miscarriage per se, however, is that $15 \%$ of the sample had a loss in the third trimester, and 5\% had neonatal deaths. In addition, the assessment on average occurred 15.1 months after the loss and during a subsequent pregnancy, when thoughts of the earlier loss may have been rekindled.

Of the studies that found a lack of association between gestational age and grief following miscarriage, Peppers and Knapp ${ }^{75}$ found no relationship between the intensity of grief and time of loss in 65 women who had a pregnancy loss. The implications of these results are weakened by the widely varying time intervals between the loss and the time the intensity of grief was assessed, and results are confounded in regard to miscarriage by the inclusion of women who experienced relatively late losses in the form of stillbirths and neonatal deaths in the sample. Deckardt et al. ${ }^{53}$ found a lack of association between gestational age and grief. Standardized questionnaires were administered to 86 patients who had experienced a spontaneous abortion shortly after they miscarried and subsequently at 7,13 , and 24 months. Intensity of grief was found to be unrelated to gestational age. Finally, Cuisinier et al. $^{76}$ compared the effect of gestational age on grief in early pregnancy loss (i.e., before 20 weeks) and in late pregnancy loss (i.e., stillbirth). Based on a sample of 143 women who experienced either a miscarriage or a stillbirth, gestational age was not found to be associated with the intensity of grief in early miscarriage but was associated with the intensity of grief in losses that occurred late in the pregnancy.

Aside from the clear need for systematic study, what can be inferred from these contradictory results? One possibility is that as the range in gestational age is relatively restricted in miscarriage, with three quarters occurring before the 12th week of gestation, ${ }^{32,33}$ gestational age is less likely to have a powerful effect on grief when women who have experienced a miscarriage are studied exclusively. ${ }^{77}$ Alternatively, gestational age may not be a primary marker of the strength of the bond or reality of the pregnancy in early miscarriage. Bowlby ${ }^{24}$ described attachment as the degree to which an individual experiences an af- 
fective connection and sense of involvement with the loved individual, object, or symbol. Perhaps the degree of psychological attachment present in an early pregnancy loss is not dependent on the literal passage of time. In support of this possibility, many women are found to have a strong attachment as soon as the pregnancy is known, ${ }^{70}$ and the majority of women have mental representations of the fetus by about 10 weeks even in the absence of independent verification through fetal imaging. ${ }^{3}$

Needs and wishes the individual associates with the pregnancy. The particular needs and wishes the individual associates with the pregnancy ought to impact the duration and intensity of grief following a miscarriage. Maternal age, often considered a potential indicator of values and goals the individual is likely to have in regard to childbearing, and number of prior losses are factors mentioned in the literature that might define the meaning of the pregnancy to the bereaved and, thus, impact the duration and intensity of grief subsequent to a miscarriage. With regard to age, grief symptoms generally associated with the loss of loved ones are greater in younger age groups perhaps because coping with death at younger ages tends to be more difficult, given that the loss is likely to be more sudden (i.e., more likely to be due to accidents and less likely to be due to disease) and, therefore, more unexpected. ${ }^{17}$

No studies could be located specifically relating grief, maternal age, and miscarriage, but Neugebauer et al. ${ }^{78}$ studied the relationship between maternal age and signs of depression in a cohort of 229 women, and no association was found. Because symptoms of grief and depression are particularly difficult to distinguish in the first 2 months postloss, ${ }^{19}$ the fact that $72 \%$ of the women in the cohort were assessed in the first month postloss provides support for a lack of association between grief and maternal age but still leaves open the possibility that a different result might be found if grief were directly assessed. In the same study, Neugebauer et al. ${ }^{78}$ also did not find that the number of prior reproductive losses had a significant effect on the incidence of major depression 1 month after a miscarriage. Based on their review of the literature on affective reactions and miscarriage, Klier et al. ${ }^{7}$ concluded that prior pregnancy loss does not seem to have a significant effect on the psychological consequences of miscarriage (defined primarily by studies measuring depressive reactions).

Extent to which the lost relationship is an important part of the bereaved individual's mental representation of the world. Investigations as to whether the importance of the pregnancy and the degree to which it was desired impact level of grief have produced mixed results. Ritsher and Neugebauer, ${ }^{11}$ in a validation study of the PBGS, assessed at 2 weeks, 6 weeks, and 6 months postloss the relationship between degree of investment in the pregnancy and intensity of grief in 304 women who suffered a miscarriage prior to 28 weeks. Women who desired the pregnancy and seemed more invested in it (indicated, for example, by endorsing such items as, I had started thinking of a name; I think of the loss as a baby; I bought things for the baby) had significantly higher PBGS scores. Beutel et al., ${ }^{3}$ on the other hand, administered standardized independent measures of grief and depression to women who experienced a spontaneous abortion. Ambivalence toward the pregnancy was significantly associated with an increase in depressive symptoms but not associated with intensity of grief reactions.

The number of living children an individual has at the time of miscarriage has also been used as a marker of the importance attached to the pregnancy, based on the assumption that the absence of living children is associated with a relatively greater desire for children and, as a result, a greater investment in the pregnancy. Janssen et al., ${ }^{74}$ in a longitudinal, prospective study, evaluated 227 women using the PGS on four occasions postloss. A highly significant positive relationship (0.01) between intensity of grief and the absence of living children was found. Similarly, women without any children had significantly higher PGF scores when assessed at 4 months, in a follow-up study of 88 women who miscarried prior to 18 weeks. ${ }^{79}$ Inferential support was also found in the study by Neugebauer et al., ${ }^{78}$ noted earlier, that examined the likelihood of major depressive disorder (MDD) following miscarriage. When the 229 women who had miscarried were administered the Diagnostic Interview Schedule, the risk for an MDD was significantly elevated in women who had miscarried and who were childless relative to a comparison group of women drawn from the community. Again, as has been noted, as $72 \%$ of the cases of MDD in this study 
began within the first month after loss, these symptoms are likely to overlap with symptoms of grief. Thus, based on these sparse data, the relationship between investment in the pregnancy and intensity of grief is inconsistent, whereas studies related to the absence of living children at the time of miscarriage seem consistent in indicating relatively higher levels of grief in women who do not have living children.

Preloss coping capacity. How well an individual has coped with emotional challenges has been considered a potential predictor of how well he or she will cope with a current emotional challenge, such as miscarriage. Thus, an individual's history of high level of emotional distress and the presence of psychiatric symptoms were expected to be associated with relatively more enduring and intense grief following pregnancy loss. Janssen et al. ${ }^{74}$ directly addressed this question in a prospective longitudinal study. They used the Dutch Personality Inventory and information about low self-esteem, general and social inadequacy, and aggrievedness to assess preloss "neurotic personality," defined as relatively high levels of emotional distress. Women who had a relatively high degree of neurotic personality and preloss psychiatric symptoms had relatively higher levels of grief based on the PGS. This result is consistent with Lasker and Toedter's review $^{80}$ of 22 studies that used the PGS and included an examination of the relationship between mental health, as indicated by scores on a wide-ranging set of psychiatric symptom rating scales, and pregnancy loss (including miscarriages, stillbirths, induced abortion, neonatal death). Intensity of grief was positively related to the presence of psychiatric symptoms.

Social support. Many studies have demonstrated that social support is associated with improved adjustment following negative life events $^{81}$ and may be related to an individual's personal appraisals of support rather than the actual supportive behaviors of others. ${ }^{82}$ There is some evidence that social support may facilitate adjustment after pregnancy loss generally ${ }^{80}$ by lessening the intensity and duration of stress, ${ }^{17}$ but no studies examining the effects of social support on grief following miscarriage could be found. Because many people wait until the end of the first trimester to announce a pregnancy, potentially supportive associates in the individual's social network may not even know about either the pregnancy or the miscarriage and, therefore, may not be able to offer comfort. Thus, the importance of enlisting social support after miscarriage is an important question that awaits further study.

One specific form of social support that has been posited as a factor in better coping with adversity is participation in a religious community. ${ }^{81}$ The literature on the relationship between participation in religion and coping with bereavement is inconsistent, however, ranging from positive to no difference to poorer coping among the religiously bereaved. ${ }^{17}$ Again, no studies could be located examining the relationship between religious participation and grief following miscarriage. Religious participation not only can affect social support, but it also can affect the individual's belief system and potentially facilitate grieving by allowing the individual to attach a meaning as to why a loss has occurred.

\section{Integrative summary}

The literature relating grief to miscarriage is extremely sparse, and as a result, few clear and consistent results are evident. Suggestively, the affective and behavioral reactions that typically occur following miscarriage seem similar to the affective and behavioral reactions that typically occur following other types of significant losses. At the same time, grief following miscarriage seems somewhat distinct from grief that typically occurs following other losses in the preponderant emphasis on times ahead rather than remembered times. Thus, after a miscarriage, the individual seems to dwell on images of an anticipated future and the hopes and dreams about what was to be rather than on past experiences. Yearning after a miscarriage also seems somewhat different in that it is primarily centered on the individual's mental construction of a relationship and future rather than actual, past, directly shared experiences.

With regard to the percentage of individuals who experience a grief reaction following a miscarriage, no clear guidelines are possible. The available literature does suggest that grief reactions are common and similar in intensity to grief following other types of losses. In addition, like grief following other types of losses, grief after miscarriage seems to abate in intensity by about 6 months and to diminish when a subsequent 
pregnancy occurs. Gender differences in relation to grief following miscarriage are evident, with men seeming to experience less intense and enduring grief than women.

Although many variables have been studied to determine their role as moderators of the intensity and duration of grief following miscarriage, few clear conclusions can be drawn. There is partial but inconsistent support for an association between perceiving the pregnancy as real and grief following miscarriage and inconsistent support for an association between gestational age and grief when other forms of pregnancy loss are excluded from study and only miscarriage is considered. The effects of two variables that might impact the desire to have a child, maternal age and number of prior reproductive losses, have not been studied specifically in regard to grief and miscarriage. A lack of association, however, is suggested based on studies of depressive reactions in the first 2 months following a miscarriage, a period in which grief and depressive reactions overlap. Studies examining other variables that might bear on the relationship among grief, the importance of the pregnancy, and the degree to which the pregnancy was desired have produced mixed results. For example, the absence of living children is suggestively but inconsistently associated with the intensity of grief following miscarriage. Somewhat consistent results are found when level of grief after miscarriage and the presence of prior psychiatric symptoms are studied, with preloss coping capacity seeming to be predictive of level of grief. Finally, the absence of studies on the effects of social support and religious participation on level of grief following miscarriage prevents any conclusions from being drawn.

\section{Research and clinical implications}

Additional research is clearly needed to address the many important questions that have been either not examined or insufficiently examined. In particular, additional research is needed to further clarify the nature of grief following miscarriage, the incidence of grief reactions, and the degree to which maternal age, number of prior pregnancy losses, amount of social support, the role of cultural beliefs, and religious participation moderates the intensity of grief subsequent to miscarriage. Ideally, these studies would employ a literature-based, operational definition of grief; a consistent interval to define when a pregnancy loss is considered a miscarriage; standardized measures of grief specific to pregnancy loss in which scale items are keyed to the definition of grief used; representative samples; and standardized assessment intervals.

Clinically, the paucity of clear information as to the incidence, characteristics, and duration of grief following miscarriage suggests that practitioners can offer only suggestive guidelines as to what constitutes an adaptive or typical reaction to miscarriage. When an individual's reactions seem to be typical, the similarity in the results of studies examining the duration and intensity of grief following miscarriage and the duration and intensity of grief following other types of significant losses supports using the general literature on grief to help guide patient expectations. For example, women who miscarry can be advised that their grief is likely to ebb by about 6 months ${ }^{23}$ and that a subsequent pregnancy is likely to be associated with a diminution in grief. ${ }^{7}$ By offering these general guidelines and comparing grief following miscarriage to grief following other significant losses, the clinician is indirectly providing validation, when needed, that a miscarriage has a high level of significance for most people and that strong feelings of grief are expectable.

Given the range of potential meanings that individuals attach to the pregnancy, motherhood, and loss after miscarriage, clinicians need to help patients articulate their "personal legacy of the loss." 83 For example, clinicians can ask when the individual first began to wish for a child (or next child), what she was hoping for or anticipating, and for descriptions of special moments that have occurred during the pregnancy and for images and fantasies that the individual has had about the expected future with the child. By helping the patient to put his or her thoughts and feelings into words and then helping organize these ideas into a coherent whole, patients may experience an increased sense of control. In addition, the patient may be better able to share his or her feelings and thoughts with others, thereby facilitating support.

Finally, given the primarily prospective, symbolic nature of loss in miscarriage, clinicians can facilitate grieving by helping the patient concretize the experience. Clinicians might ask patients if they have named the baby, inquire as to the name, and, with permission, use the name when discussing the loss. Developing ways to 
memorialize the baby can also help increase the reality of the loss and create mementos and memories. Clinicians can suggest that patients place material goods bought for the baby in a keepsake box, along with, for example, the sonogram and a letter the individual might write describing the hopes and dreams that she or he had for the baby. Clinicians can also assist in designing a memorial service that structures and concretizes the event, provides validation that a significant loss has occurred, and establishes an opportunity for others to acknowledge the loss and offer support. In addition, the memorial service may be valuable in marking time, providing a means to indicate the end of one phase and the beginning of a new one. ${ }^{84}$

\section{DISCLOSURE STATEMENT}

No competing financial interests exist.

\section{REFERENCES}

1. Shapiro, S. Infertility and pregnancy loss. San Francisco: Jossey-Bass, 1988.

2. Moohan J, Ashe RG, Cecil R. The management of miscarriage: Results from a survey at one hospital. J Reprod Infant Psychol 1994;12:1.

3. Beutel M, Deckardt R, von Rad M, Weiner H. Grief and depression after miscarriage: Their separation, antecedents, and course. Psychosom Med 1995;57:517.

4. Glazer ES. Miscarriage and its aftermath. In: Leiblum SR, ed. Infertility: Psychological issues and counseling strategies. New York: Wiley and Sons. 1997:230.

5. Brier N. Understanding and managing the emotional reactions to a miscarriage. Obstet Gynecol 1997:93, 151.

6. Leon IG. Perinatal loss. In: Stodland NL, Stewart DE, eds. Psychological aspects of women's health care: The interface between psychiatry, obstetrics, and gynecology, 2nd ed. Washington, DC: American Psychological Association, 2001:141.

7. Klier CM, Geller PA, Ritsher JB. Affective disorders in the aftermath of miscarriage: A comprehensive review. Arch Womens Ment Health 2002;5:129.

8. Shaver PR, Tancredy CM. Emotion, attachment, and bereavement: A conceptual commentary. In: Stroebe MS, Hansson RO, Stroebe W, Schmit H, eds. Handbook of bereavement research: Consequences, coping and care. Washington, DC: American Psychological Association, 2001:63.

9. Prigerson HG, Sheas MK, Jacob SC, Reynolds CF, Maciejewski PK. Consensus criteria for traumatic grief: A preliminary empirical test. Br J Psychiatry 1999: $174 ; 67$.
10. Beutel M, Willner H, Volkl K, von Rad M, Weiner H. Assessment of grief after pregnancy loss: Development and initial results of the validity of the Munich Grief Scale. Psychother Psychosom Med Psychol 1995;45:295.

11. Ritsher JB, Neugebauer R. Perinatal Grief Scale: Distinguishing grief from depression following miscarriage. Assessment 2002;9:31.

12. Prigerson HG, Bierhals AJ, Kasl SV, et al. Traumatic grief as a risk factor for mental and physical morbidity. Am J Psychiatry 1997;154:616.

13. Zisook S, Devaul RA, Click MA Jr. Measuring symptoms of grief and bereavement. Am J Psychiatry 1982:139;1570.

14. Covington SN. Pregnancy loss. In: Barnes LH, Covingtons SN, eds. Infertility counseling: A comprehensive handbook for clinicians. New York: Pantheon, 1999:227.

15. Prigerson HG, Jacobs SC. Caring for bereaved patients. JAMA 2001;286:1369.

16. Weiss R. Grief, bonds, and relationships. In: Stoebe MS, Hansson RO, Stroebe W, Schut H, eds. Handbook of bereavement research: Consequences, coping, and care. Washington, DC: American Psychological Association, 2001:41.

17. Stroebe W, Schmit H. Risk factors in bereavement outcome: A methodological and empirical review. In: Stroebe MS, Hansson RO, Stroebe W, Schmit H, eds. Handbook of bereavement research: Consequences, coping and care. Washington, DC: American Psychological Association, 2001:349.

18. Hughes P, Riches S. Psychological aspects of perinatal loss. Curr Opin Obstet Gynecol 2003;15:107.

19. American Psychiatric Association. Diagnostic and statistical manual of mental disorders, 4th ed. DSM-IV. Washington, DC: American Psychiatric Association, 1994.

20. Hofer MA. Relationships as regulators: A psychobiologic perspective on bereavement. Psychosom Med 1984;46:183.

21. Horowitz MJ, Siegal B, Holen A, Bonanno GA, Mulbrath $\mathrm{C}$, Stinson $\mathrm{CH}$. Diagnostic criteria for complicated grief. Am J Psychiatry 1997;154:904.

22. Prigerson HG, Frank E, Kasl SV, Reynolds CF, Andersen B. Complicated grief and bereavement related depression as distinct disorders: Preliminary empirical validation in elderly bereaved spouses. Am J Psychiatry 1995;152:23.

23. Maciejewski PK, Bahoui Z, Block SD, Prigerson HG. An empirical examination of the stage theory of grief. JAMA 2007;297:716.

24. Bowlby J. Attachment and loss. Vol. 3: Loss, sadness, and depression. New York: Basic Books, 1980.

25. Archer J. Broad and narrow perspective in grief theory: Comment on Bonnano and Kaltman (1999). Psychol Bull 2001;127:554.

26. Bowlby J. Process of morning. Int J Psychoanal 1961; 42:317.

27. Parkes CM. Coping with loss: Bereavement in adult life. BMJ 1983;316:856. 
28. Jacobs S. Pathological grief: Maladaption to loss. Washington, DC: American Psychiatric Association, 1993.

29. Fogel CI. Common symptoms: Bleeding, pain and discharge. In: Fogel CI, Woods NF, eds. Women's health care: A comprehensive handbook. London: Sage, 1995:526.

30. Hemminki E, Forssas E. Epidemiology of miscarriage and its relation to other reproductive events in Finland. Am J Obstet Gynecol 1999;18:396.

31. Griebel CP, Halvorsen J, Golemon TB, Day AA. Management of spontaneous abortion. Am Fam Physician 2005;72:1243.

32. Plater D. Taking control: How to aim for a successful pregnancy after a miscarriage. New South Wales: Transworld Publishers, 1997.

33. Cramer DW, Wise LA. The epidemiology of recurrent pregnancy loss. Semin Reprod Med 2000;18:331.

34. Neugebauer R, Kline J, O'Connor P, et al. Determinants of depressive symptoms in the early weeks after miscarriage. Am J Public Health 1992;82:1332.

35. Chung PH, Yeko TR. Recurrent miscarriage: Cause and management. Hosp Pract 1996:31:157.

36. Nybo Anderson AM, Wohlfahrt J, Christens P, Olsen J, Melbye M. Maternal age and fetus loss: Population based register linkage study. BMJ 2000;320:1708.

37. Nikcevic AV, Snijders R, Nicolardes KH, Kupek E. Some psychometric properties of the Texas Grief Inventory adjusted for miscarriage. Br J Med Psychol 1999;72:171.

38. Toedter LJ, Lasker JN, Alhadeff JM. The Perinatal Grief Scale: Development and initial validation. Am J Orthopsychiatry 1988;58:435.

39. Potvin L, Lasker J, Toedter L. Measuring grief: A short version of the Perinatal Grief Scale. I Psychopathol Behav Assess 1989;11:29.

40. Hutti MH, dePacheco M, Smith M. A study of miscarriage: Development and validation of the Perinatal Grief Intensity Scale. J Obstet Gynecol Neonat Nurs 1989;27:547.

41. Wall-Hads CL. Women's perceptions of first trimester spontaneous abortion. I Obstet Gynecol Neonat Nurs 1985;14:50.

42. Toedter LJ, Lasker JN, Janssen HJ. International comparison on studies using the perinatal grief scale: A decade of research on pregnancy loss. Death Stud 2001;25:205.

43. Bansen SS, Stevens HA. Women's experiences of miscarriage in early pregnancy. J Nurs Midwif 1992;37:84.

44. Abboud LN, Liamputtong P. Pregnancy loss: What it means to women who miscarry and their partners. Soc Work Health Care 2003;36:37.

45. Adolfsson A, Larsson PG, Wijina B, Bertero C. Guilt and emptiness: Women's experiences of miscarriage. Health Care Wom Int 2004;25:543.

46. Tomita T, Kitamura T. Clinical and research measures of grief: A reconsideration. Compr Psychiatry 2002;43:95.

47. Stirtzinger RM, Robinson GE, Stewart DE, Ralevaki E. Parameters of grieving in spontaneous abortion. Int J Psychiatry Med 1999;29:235.
48. Madden ME. The variety of emotional reactions to miscarriage. Women Health 1994;21:85.

49. Leppert PC, Pahlka BS. Grieving characteristics after spontaneous abortion: A management approach. $\underline{\mathrm{Ob}-}$ stet Gynecol 1984;64:119.

50. Turner MJ, Falnnelly GM, Wingfield M. The miscarriage clinic: An audit of the first year. $\mathrm{BrJ}$ Obstet $\mathrm{Gy}-$ naecol 1991;98:306.

51. Zaccardi R, Abbott J, Kozial-McLain J. Loss and grief reactions after spontaneous miscarriage in the emergency department. Ann Emerg Med 1993;22:799.

52. Paton F, Wood R, Bor R, Nitsun M. Grief in miscarriage patients and satisfaction with care in a London hospital. J Reprod Infant Psychol 1999;17:301.

53. Deckardt R, Beutel M, Schaudig K. Long-term psychological sequelae of spontaneous abortion: Do medical management, recent pregnancy and delivery really help in coping with grief? Geburtshilfe Frauenheilk 1994;54:347.

54. Cuisinier M, Janssen H, DeGraauw C, Baker S, Hoogdiun CA. Pregnancy following miscarriage: Course of grief and some determining factors. I Psychosom Obstet Gynecol 1996;17:168.

55. Nikcevic AV, Tunkel SA, Kuczmierczyk AR, Nicolaides $\mathrm{KH}$. Investigation of the course of miscarriage and its influence on women's psychological distress. Br J Obstet Gynaecol 1999;106:808.

56. Franche R. Psychological and obstetric predictors of couples' grief during pregnancy after miscarriage or perinatal death. Obstet Gynecol 2001;97:597.

57. Goldbach KRC, Dunn DS, Toedter LJ, Lasker JN. The effects of gestational age and gender on grief after pregnancy loss. Am J Orthopsychiatry 1991;61:461.

58. Stinson KM, Lasker JN, Lohman J, Toedter LJ. Parents grief following pregnancy loss: A comparison of mothers and fathers. Fam Relations 1992;41:218.

59. Beutel M, Willner H, Deckardt R, VonRad M, Weiner H. Similarities and differences in couples' grief reactions following a miscarriage: Results from a longitudinal study. J Psychosom Res 1996;40:245.

60. Alderman L. The psychological experience of miscarriage on women and their families. Dissertation $\mathrm{Ab}-$ stracts International: Section B: Sciences and engineering. 1996;57(4-B):2853.

61. Alderman L, Chisholm J, Denmark F, Seilbod SC. Bereavement and stress of a miscarriage: As it affects the couple. Omega: J Death Dying 1998;37:317.

62. Barragan T, Antonio J. Miscarriage: Grief reaction differences between Mexican Americans and EuroAmericans on the Perinatal Grief Scale. Dissertation Abstracts International: Section B: Sciences and engineering. 2005;66(3-B):1706.

63. Swanson KM, Wojnar D, Petras A, Hsien-Tzu C. Gender differences in grief, depression and satisfaction with support after miscarriage. Paper presented at the 16th International Nursing Research Congress, Renew Nursing through Scholarship, July 14-16, 2005, Hawaii.

64. Serrano F, Luisa ML. Recurrent miscarriage: Psychological and relational consequences for couples. Psychol Psychother 2006;79:585. 
65. Johnson MP, Puddifoot JE. The grief response in the partners who miscarry. Br J Med Psychol 1996;69:313.

66. Puddifoot JE, Johnson MP. Miscarriage: Is vividness of visual imagery a factor in the grief reaction of the partner? Br J Health Psychol 1998;3:137.

67. Conway K, Russell, G. Couples' grief and experience of support in the aftermath of miscarriage. $\mathrm{Br} \mathrm{J} \mathrm{Med}$ Psychol 2000;73:531.

68. Puddifoot JE, Johnson MP. The legitimacy of grieving: The partners experience at miscarriage. Soc Sci Med 1997;45:837.

69. Puddifoot JE, Johnson MP. Active grief, despair, and difficulty coping: Some measured characteristics of male response following their partner's miscarriage. J Reprod Infant Psychol 1999;17:89.

70. Muller ME. A critical review of prenatal attachment research. Scholarly Inquiry Nurs Pract 1992;6:5.

71. Hutti MH. Parents' perceptions of the miscarriage experience. Death Stud 1992;16:401.

72. Ritsher JB, Neugebauer R. Mourning and miscarriage: The cardinal role of yearning for the lost child in the grief process following reproductive loss. Presented at the First World Congress on Women's Mental Health, March 2001, Berlin (cited in ref. 7).

73. Theut SK, Pedersen FA, Zaslow MJ, Rabinovich BA. Pregnancy subsequent to perinatal loss: Parental anxiety and depression. I Acad Child Adolesc Psychiatry 1988;27:289.

74. Janssen HJ, Cusinier MC, deGraauw KP, Hoodgiun KA. A prospective study of risk factors predicting grief intensity following pregnancy loss. Arch Gen Psychiatry 1997;54:56.

75. Peppers LG, Knapp RJ. Maternal reactions to involuntary fetal/infant death. Psychiatry 1980;43:155.

76. Cuisiner MC, Kiupers JC, Hoogdiun CA, deGraauw $\mathrm{CP}$, Janseen HJ. Miscarriage and stillbirth: Time since the loss, grief intensity and satisfaction with care. Eur J Obstet Gynecol Reprod Biol 1993;52:163.
77. Swanson KM. Effects of caring, measurement, and time on miscarriage impact and woman's well-being. Nurs Res 1999;48:288.

78. Neugebauer R, Kline J, Shrout P, et al. Major depressive disorder in the six months after miscarriage. JAMA 1997;277:383.

79. Adolfsson A, Bertero C, Larsson P. Effect of a structured follow-up visit to a midwife on women with early miscarriage: A randomized study. Obstet Gynecol 2006;85:330.

80. Lasker JN, Toedter LJ. Predicting outcomes after pregnancy loss: Results from studies using the Perinatal Grief Scale. Illness Crisis Loss 2000;8:350.

81. McKintosh DN, Silver RC, Wortman CB. Religion's role in adjusting to a negative life event: Coping with the loss of a child. J Pers Soc Psychol 1993;65:812.

82. Lehman DR, Ellard JH, Wortman CB. Social support for the bereaved: Recipients' and providers' perspectives on what is helpful. J Consult Clin Psychol 1986;54:438.

83. Cosgrove L. The aftermath of pregnancy loss: A feminist critique of the literature and implications for treatment. In: Chrisler JC, ed. From menarche to menopause: The female body in feminist therapy. New York: Haworth Press, 2004:107.

84. Brin $\mathrm{D}$. The use of rituals in grieving for a miscarriage or stillbirth. Women Ther 2004;27:123.

Address reprint requests to: Norman Brier, Ph.D.

Clinical Professor of Psychiatry and Pediatrics Albert Einstein College of Medicine of Yeshiva University

Children's Evaluation and Rehabilitation Center 1410 Pelham Parkway South Bronx, NY 10461

E-mail: brier@aecom.yu.edu 